\title{
Projection Neurons with Shared Cotransmitters Elicit Different Motor Patterns from the Same Neural Circuit
}

\author{
Debra E. Wood, Wolfgang Stein, and Michael P. Nusbaum \\ Department of Neuroscience, University of Pennsylvania School of Medicine, Philadelphia, Pennsylvania 19104-6074
}

\begin{abstract}
Specificity in the actions of different modulatory neurons is often attributed to their having distinct cotransmitter complements. We are assessing the validity of this hypothesis with the stomatogastric nervous system of the crab Cancer borealis. In this nervous system, the stomatogastric ganglion (STG) contains a multifunctional network that generates the gastric mill and pyloric rhythms. Two identified projection neurons [modulatory proctolin neuron (MPN) and modulatory commissural neuron 1 (MCN1)] that innervate the STG and modulate these rhythms contain GABA and the pentapeptide proctolin, but only MCN1 contains Cancer borealis tachykinin-related peptide (CabTRP la). Selective activation of each projection neuron elicits different rhythms from the STG. MPN elicits only a pyloric rhythm, whereas MCN1 elicits a distinct pyloric rhythm as well as a gastric mill rhythm. We tested the degree to which CabTRP la distinguishes the actions of MCN1 and MPN. To this end, we used the tachykinin
\end{abstract}

receptor antagonist Spantide I to eliminate the actions of CabTRP la. With Spantide I present, MCN1 no longer elicited the gastric mill rhythm and the resulting pyloric rhythm was changed. Although this rhythm was more similar to the MPN-elicited pyloric rhythm, these rhythms remained different. Thus, CabTRP la partially confers the differences in rhythm generation resulting from MPN versus MCN1 activation. This result suggests that different projection neurons may use the same cotransmitters differently to elicit distinct pyloric rhythms. It also supports the hypothesis that different projection neurons use a combination of strategies, including using distinct cotransmitter complements, to elicit different outputs from the same neuronal network.

Key words: neuropeptides; tachykinin; proctolin; stomatogastric nervous system; crustacea; neuromodulation; motor pattern generation
The prevalence of colocalized neurotransmitters suggests that the combination of transmitters released by a neuron attributes specificity to its actions (Hokfelt, 1991; Agnati et al., 1995; Brezina and Weiss, 1997; Marder et al., 1997). However, the extent to which this hypothesis explains the distinct actions of different input neurons influencing a single neuronal network has not been examined. This is because there are few systems containing multiple identified neurons that influence the same network and have identified cotransmitters (Kulhman et al., 1985a,b; Thorogood and Brodfuehrer, 1995; McCrohan and Croll, 1997; Blitz et al., 1999). Peptidergic neurons in particular may require distinct cotransmitters to specify their actions, because neurally released peptides commonly have a broad sphere of influence, potentially giving them access to all relevant receptors. This is a result of their release from nonsynaptic sites and their ability to diff use relatively long distances to reach their target receptors (Jan and Jan, 1982; Mayeri et al., 1985; Agnati et al., 1995; Zupanc, 1996).

We aim to understand how different peptidergic projection neurons elicit distinct motor patterns from a multifunctional network. The stomatogastric nervous system (STNS) of the crab Cancer borealis is well suited for this study because it contains well characterized pattern generating circuits in the stomatogastric ganglion (STG) (Harris-Warrick et al., 1992). In the C. borealis STG, the gastric mill and pyloric rhythms are generated by distinct circuits composed of overlapping sets of neurons (Weimann et al., 1991; Weimann and Marder, 1994). Different versions of these rhythms are elicited by selective stimulation of different modulatory projection neurons that innervate the STG (Norris et al., 1994, 1996; Blitz et al., 1999). For example, modulatory commissural neuron 1

Received May 12, 2000; revised Aug. 29, 2000; accepted Sept. 21, 2000.

This work was supported by National Science Foundation Grant IBN-9808356 (M.P.N.) and National Institute of Neurological Disorders and Strokes Grant NS29436 (M.P.N.). We thank Dr. Dawn M. Blitz for helpful discussions and for comments on earlier versions of this paper.

Correspondence should be addressed to Dr. Michael P. Nusbaum, Department of Neuroscience, University of Pennsylvania School of Medicine, 215 Stemmler Hall, Philadelphia, PA 19104-6074. E-mail: nusbaum@mail.med.upenn.edu.

Copyright (C) 2000 Society for Neuroscience $0270-6474 / 00 / 208943-11 \$ 15.00 / 0$
(MCN1) elicits both gastric mill and pyloric rhythms (Coleman and Nusbaum, 1994; Bartos and Nusbaum, 1997; Bartos et al., 1999), whereas the modulatory proctolin neuron (MPN) elicits a pyloric rhythm but no gastric mill rhythm (Blitz and Nusbaum, 1997; Blitz et al., 1999). Both neurons contain GABA and the peptide proctolin (Nusbaum and Marder, 1989a; Blitz et al., 1999). MCN1 also contains Cancer borealis tachykinin-related peptide Ia (CabTRP Ia) (Blitz et al., 1999).

Bath-applied proctolin and MPN stimulation produce the same pyloric rhythm (Nusbaum and Marder, 1989b). Because neurally released peptides have a relatively broad sphere of influence, proctolin may have the same actions on the pyloric circuit regardless of the projection neuron from which it is released. If so, then the distinct actions of MCN1 may result from its peptide cotransmitter, CabTRP Ia. We tested this possibility by comparing the MCN1- and MPN-elicited rhythms in the presence of Spantide I, a tachykinin receptor antagonist (Folkers et al., 1984; Christie et al., 1997a; Nässel, 1999). Under this condition, the actions of MPN were not changed, but MCN1 elicited an altered pyloric rhythm and no longer elicited the gastric mill rhythm. The altered pyloric rhythm was more similar to, but still distinct from the MPN-elicited pyloric rhythm. Thus, the peptide cotransmitter CabTRP Ia contributes to, but does not completely account for the distinct rhythms elicited by these two projection neurons.

Parts of this work appeared previously in abstract form (Wood and Nusbaum, 1998).

\section{MATERIALS AND METHODS}

Animals. Adult male crabs (C. borealis) were purchased from the Marine Biological Laboratory (Woods Hole, MA) and from commercial sources (Boston, MA). Crabs were maintained in filtered, aerated artificial seawater $\left(10-12^{\circ} \mathrm{C}\right)$. Animals were anesthetized by packing them in ice for 20-40 min before dissection. The dissection of the STNS was done in physiological saline at $\sim 4^{\circ} \mathrm{C}$ as described previously (Blitz and Nusbaum, 1997). Experiments were performed on the isolated STNS (Fig. 1 $A$ ). Data were obtained from 91 animals.

Solutions. C. borealis physiological saline had the following composition (in mM): $\mathrm{NaCl}, 440 ; \mathrm{MgCl}_{2}, 26 ; \mathrm{CaCl}_{2}, 13 ; \mathrm{KCl}, 11$; Trisma base, 10; maleic acid, 5; pH 7.4-7.6. Spantide I was obtained from Peninsula Laboratories (Belmont, CA), Sigma (St. Louis, MO), or was synthesized at the 


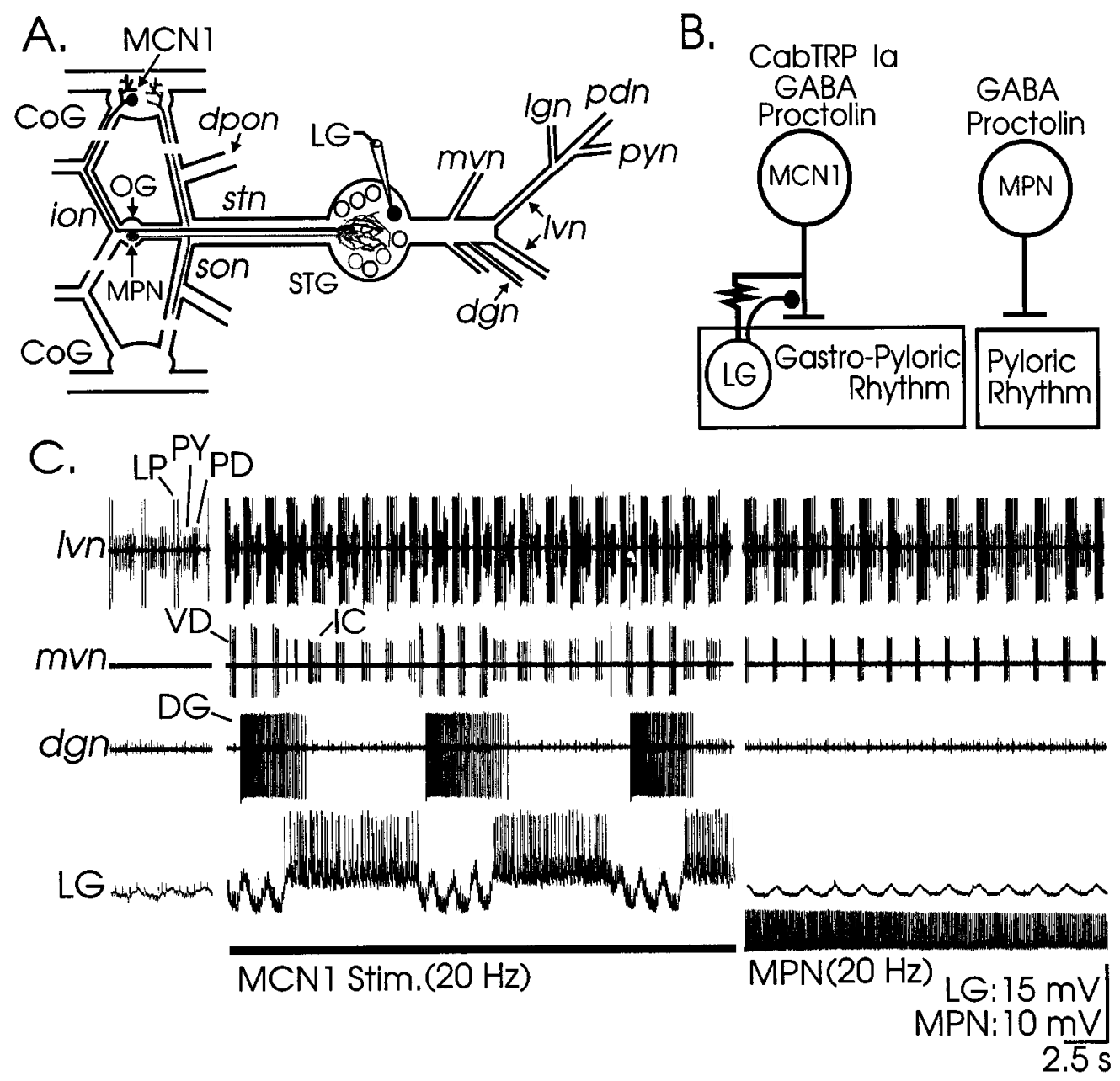

Figure 1. Schematic of the stomatogastric nervous system and the response of the gastric mill and pyloric circuits to individual stimulation of two different modulatory projection neurons. $A$. The stomatogastric nervous system includes four ganglia plus their connecting and peripheral nerves. The ganglia are the stomatogastric ganglion $(S T G)$, oesophageal ganglion $(O G)$, and the paired commissural ganglia $(C o G s)$. The STG contains the gastric mill and pyloric circuits, whereas modulatory projection neurons that innervate the STG are located in the OG and CoGs. Modulatory commissural neuron 1 (MCN1) occurs as a single copy in each CoG, whereas the modulatory proctolin neuron $(M P N)$ occurs as an equivalent pair of somata in the OG. The axonal projection patterns of only one MCN1 and MPN are shown. The inferior (ion) and superior oesophageal nerves (son) are severed (as indicated by the broken lines) to eliminate the modulatory influence from $\mathrm{CoG}$ projection neurons that innervate the STG. Anterior is to the left. B, Schematic of the cotransmitter complements of MCN1 and MPN, plus their actions on the STG circuits. Also illustrated are the two synaptic actions that occur onto the STG terminals of MCN1 that are pivotal for enabling this neuron to elicit the gastric mill rhythm (Coleman et al., 1995; Blitz et al., 1999). T-bars represent transmitter-mediated excitation, filled circle represents synaptic inhibition, and resistor symbol represents electrical coupling. $C$, Tonic stimulation of MCN1 and MPN elicits distinct STG motor patterns. MCN1 stimulation enhances and modifies the pyloric rhythm (lvn, $m v n)$ and activates the gastric mill rhythm $(d g n, L G)$. MPN stimulation enhances and modifies the pyloric rhythm but does not activate a gastric mill rhythm. Note that the pyloric rhythm during stimulation of these two projection neurons is distinct (e.g., $m v n$ ). Most hyperpolarized LG $V_{\mathrm{m}}$ : saline superfusion (left), $-66 \mathrm{mV}$; MCN1 stimulation (middle), $-72 \mathrm{mV}$; MPN stimulation (right), $-69 \mathrm{mV}$. Nerves: dpon, dorsal posterior oesophageal nerve; dgn, dorsal gastric nerve; ion, inferior oesophageal nerve; lgn, lateral gastric nerve; lvn, lateral ventricular nerve; $m v n$, medial ventricular nerve; $p d n$, pyloric dilator nerve; $p y n$, pyloric constrictor nerve; son, superior oesophageal nerve; stn, stomatogastric nerve. STG neurons: $D G$, dorsal gastric neuron; $I C$, inferior cardiac neuron; $L G$, lateral gastric neuron; $L P$, lateral pyloric neuron; $P D$, pyloric dilator neuron; $P Y$, pyloric neuron; $V D$, ventricular dilator neuron.

Cancer Research Center, University of Pennsylvania School of Medicine (Philadelphia, PA). Spantide solutions were made by dissolving Spantide I into $C$. borealis physiological saline. Each application of Spantide I was continued for at least $15-20 \mathrm{~min}$ before stimulation of MCN1 or MPN Preparations were washed by superfusing saline for at least $40 \mathrm{~min}$ before postapplication controls were performed.

Neuropeptide applications. CabTRP Ia $\left(10^{-4} \mathrm{M}\right.$ in pipette) and proctolin $\left(10^{-4} \mathrm{M}\right.$ in pipette) were separately pressure-ejected (2-4 sec duration, 6 PSI) onto the desheathed STG neuropil using a Picospritzer II (General Valve, Fairfield, NJ). Pressure pipettes had resistances of 1-2 M $\Omega$.

Electrophysiology. Electrophysiology was performed using standard methods as described previously (Bartos and Nusbaum, 1997; Blitz and Nusbaum, 1997). The STNS was pinned down in a silicone elastomer-lined (SYLGARD 184; KR Anderson, Santa Clara, CA) Petri dish and superfused continuously $(7-12 \mathrm{ml} / \mathrm{min}$ ) with chilled physiological saline (10$13^{\circ} \mathrm{C}$ ). To facilitate intracellular recordings and access for applied solutions, the STG and the oesophageal ganglion (OG) were desheathed and visualized with white light transmitted through a dark-field condenser (Nikon, Tokyo, Japan). Microelectrodes (15-30 M $\Omega$ ) were filled with $4 \mathrm{M}$ potassium acetate plus $20 \mathrm{~mm} \mathrm{KCl}$. Intracellular current injections were accomplished using Axoclamp 2 (Axon instruments, Foster City, CA) amplifiers in single-electrode discontinuous current-clamp (DCC) mode. Sample rates in DCC mode ranged from 2 to $3 \mathrm{kHz}$.

Identification of STG neurons was done by documenting their activity patterns, synaptic interactions, and axonal projection paths as described previously (Weimann et al., 1991; Bartos and Nusbaum, 1997; Blitz and Nusbaum, 1997). Identification of the projection neurons MPN and MCN1 was made on the basis of their soma (MPN, Nusbaum and Marder, 1989a,b) or axon location (MCN1, Coleman and Nusbaum, 1994; Bartos and Nusbaum, 1997) and their interactions in the STG (Blitz et al., 1999). In most experiments, modulatory influence from projection neurons in the commissural ganglia (CoGs) onto the STG was eliminated by transecting both inferior (ions) and superior oesophageal nerves (sons) (Fig. 1A). Under these conditions the pyloric rhythm either stops or slows $(0.2-0.8$ $\mathrm{Hz}$ ) from cycle frequencies that are typically faster than $1 \mathrm{~Hz}$. If it was active before transection, the gastric mill rhythm always terminated after transection. Selective activation of MCN1 was achieved by tonically stimulating the ion or ions $(10-20 \mathrm{~Hz}$ ) (Coleman et al., 1995; Bartos and Nusbaum, 1997). Stimulation of the sensory pathway contained in the dorsal oesophageal posterior nerve (dpon) was used to elicit a gastric mill rhythm that is distinct from the MCN1-elicited gastric mill rhythm (Blitz et al., 1998; Beenhakker et al., 2000). The dpons were stimulated in a 0.06 
$\mathrm{Hz}$ train (15 Hz intraburst, $6 \mathrm{sec}$ duration) for $2.5-3 \mathrm{~min}$. In the dpon stimulation experiments, the ions were transected, but the sons were left intact so that the influence of the activated sensory pathway, as well as CoG projection neurons other than MCN1, still reached the STG.

The pyloric cycle period was defined as the interval between the onset of an impulse burst in the pyloric dilator neuron (PD) and the onset of the subsequent PD neuron burst. Pyloric cycle frequency was determined as the reciprocal of the pyloric cycle period. Extracellular recordings were used to determine the mean number of action potentials per burst and the intraburst firing frequency for several pyloric neurons including the lateral pyloric (LP), inferior cardiac (IC), and ventricular dilator (VD) neurons. LP neuron activity was assessed from the lateral ventricular nerve (lvn), whereas IC and VD neuron activity was measured from the medial ventricular nerve $(m v n)$ (Fig. $1 C$ ). For phase analysis, the activity of the $\mathrm{PD}$ and lateral posterior gastric (LPG) neurons was also determined. PD neuron activity was monitored from the pyloric dilator nerve $(p d n)$, whereas LPG neuron activity was determined from intracellular recordings (Fig. $1 A$ ). Mean values for all pyloric-related parameters were determined from measurements of 20 consecutive cycles of pyloric activity. In all experiments, MCN1 activity was controlled directly by the stimulation protocol, as each extracellular stimulation (duration, $1 \mathrm{msec}$ ) elicited a single action potential from MCN1 (Coleman et al., 1995; Bartos and Nusbaum, 1997). Data analysis during MPN stimulation came from stretches during which MPN maintained a consistent firing frequency $(15-20 \mathrm{~Hz})$ over the sample interval.

The gastric mill rhythm was monitored by activity in the lateral gastric (LG) and dorsal gastric (DG) neurons. The LG neuron was recorded either extracellularly from the lateral gastric nerve $(\lg n)$ or intracellularly, and the DG neuron was recorded extracellularly from the dorsal gastric nerve $(d g n)$ (Fig. 1A). Ten consecutive gastric mill cycles $(10$ cycles of LG neuron bursting) were used for computing both the mean number of action potentials per LG neuron burst and the mean value for the gastric mill cycle period.

Data analysis. Data were recorded onto videotape (Vetter Instruments Rebersburg, PA) and chart recorder (Astromed MT-95000; Astro-Med/ Grass Inc., West Warwick, RI). Figures were prepared by scanning sequences of recordings using a Hewlett Packard Scanjet IIc with Deskscan II (version 2.0) software. Final figures were prepared with CorelDraw (version 3.0 for Windows). Graphics and statistics were generated using Sigma Plot 4.0 and Sigma Stat 2.03 (SPSS, Chicago, IL). Statistical tests used to analyze data were one-way ANOVA, repeated measures ANOVA, or Friedman repeated measures ANOVA on ranks (with Tukey's test for multiple comparisons). Data are presented as means $\pm \mathrm{SD}$.

\section{RESULTS}

\section{Comparison of the MCN1- and MPN-elicited STG rhythms}

Selective stimulation of MCN1 and MPN elicits different motor patterns from the STG network, whether or not the CoGs remain connected with the STG (Nusbaum and Marder, 1989b; Coleman and Nusbaum, 1994; Bartos and Nusbaum, 1997; Blitz et al., 1999). Our aim was to determine the extent to which these different motor patterns resulted from the actions of CabTRP Ia released by MCN1 within the STG. Therefore, to avoid the complication resulting from the synaptic actions of MPN on MCN1 in the CoGs (Blitz and Nusbaum, 1997), we compared these rhythms in preparations in which the CoGs were removed by transection of the ions and sons (Fig. 1A).

MCN1 stimulation elicits specific gastric mill and pyloric rhythms (Coleman et al., 1995; Bartos and Nusbaum, 1997; Blitz et al., 1999), whereas MPN elicits only a pyloric rhythm, which is distinct from the MCN1-elicited pyloric rhythm (Nusbaum and Marder, 1989b; Blitz and Nusbaum, 1997; Blitz et al., 1999) (Fig. $1 B, C)$. Furthermore, some STG network neurons are activated only during MCN1 stimulation. This includes the LG, DG, and VD neurons (Fig. $1 C$ ). The LG and DG neurons are generally active only with the gastric mill rhythm (Weimann et al., 1991). The VD neuron is generally active with both the pyloric and gastric mill rhythms, yet is not activated by MPN stimulation with the CoGs disconnected (Nusbaum and Marder, 1989b; Weimann et al., 1991).

The differences in the pyloric rhythms elicited by these two projection neurons include distinct phase relationships among the pyloric circuit neurons (Blitz et al., 1999). We found that there were also differences in the pyloric cycle frequency and the activity levels of individual pyloric neurons (Fig. $2 A, B$ ). For example, the pyloric cycle frequency is increased significantly, relative to the prestimulation level, by both MPN and MCN1 activation $(p<0.05$; MPN, $n=17$; MCN1, $n=44$ ) (Fig. $2 B$ ). However, during comparable stimulation rates $(20 \mathrm{~Hz}), \mathrm{MCN} 1$ elicits a faster pyloric rhythm than MPN $(p<0.05)$ (Fig. $2 B)$. Additionally, whereas both MPN and MCN1 enhance the activity of the LP and IC neurons, these neurons fire significantly more spikes per burst during the MPNelicited pyloric rhythm $(p<0.05)$ (Fig. $2 B)$. In contrast, the VD neuron is significantly more active during the MCN1-elicited pyloric rhythm $(p<0.05)$ (Fig. $2 B)$. Note also that, during MCN1 stimulation, there are additional rhythmic changes in the activity levels of the IC and VD neurons that occur regularly across several pyloric cycles. These rhythmic changes occur because these two STG neurons also participate in the gastric mill rhythm that is elicited by MCN1 stimulation (Figs. $1 C, 2 A$ ).

\section{Spantide I blocks the effects of neurally released CabTRP la}

MPN and MCN1 share two transmitters, GABA and the peptide proctolin, whereas MCN1 also contains the peptide cotransmitter CabTRP Ia (Fig. 1B; Blitz et al., 1999). We therefore aimed to determine whether the different STG circuit responses to MPN and MCN1 stimulation resulted from the actions of CabTRP Ia. To this end, we studied the STG response to MCN1 stimulation in the presence of the broad spectrum tachykinin receptor antagonist Spantide I (Folkers et al., 1984; Nässel, 1999). We showed previously that Spantide I blocks the actions of bath applied CabTRP Ia, but not proctolin, on the STG (Christie et al., 1997a).

Spantide I $\left(2 \times 10^{-5} \mathrm{M}\right)$ effectively and reversibly diminished the actions of MCN1 stimulation on the gastric mill and pyloric rhythms (Fig. 3). In the absence of MCN1 stimulation, the gastric mill rhythm is never spontaneously active with the CoGs disconnected. Under these conditions, MCN1 stimulation routinely activates this rhythm (Coleman and Nusbaum, 1994). During MCN1 stimulation in the presence of Spantide I, however, the gastric mill rhythm was no longer activated ( $n=41$ of 41) (Fig. 3). This inability to elicit the gastric mill rhythm appeared to result primarily from the reduction or elimination of the CabTRP Ia-mediated actions of MCN1 on the LG neuron. The LG neuron receives both modulatory and electrical excitation from MCN1 (Coleman et al., 1995). This excitation is necessary for generation of this gastric mill rhythm (Coleman et al., 1995; Nadim et al., 1998; Bartos et al., 1999). In many of these preparations (30 of 41, 73\%), Spantide I superfusion completely eliminated LG neuron impulse activity in response to MCN1 stimulation. All that remained of the LG neuron response to $\mathrm{MCN} 1$ stimulation in these preparations were the EPSPs resulting from their electrical coupling (Fig. 3). In the remaining preparations (11 of $41,27 \%$ ), there was weak and intermittent spiking in the LG neuron when MCN1 was stimulated.

Another consistent consequence of MCN1 stimulation during Spantide I application was that DG neuron activity switched from rhythmic impulse bursts to tonic firing (83\% of preparations; $n=$ 24) (Fig. 3). Although the timing of DG neuron bursts during the gastric mill rhythm is regulated by LG neuron activity, DG rhythmicity during MCN1 stimulation normally persists when the LG neuron is hyperpolarized, and the gastric mill rhythm is thereby suppressed (Coleman and Nusbaum, 1994).

The pyloric system response to MCN1 stimulation was also consistently weakened by the application of Spantide I (Fig. 3). This included a significantly slower pyloric cycle frequency and weaker activity in at least several pyloric circuit neurons (Fig. 4). The pyloric cycle frequency was reduced from $0.93 \pm 0.12 \mathrm{~Hz}$ during MCN1 stimulation in normal saline to $0.78 \pm 0.13 \mathrm{~Hz}(p<$ $0.001 ; n=29$ ) when the stimulation occurred during Spantide I superfusion. The cycle frequency occurring during MCN1 stimulation with Spantide I present did, however, remain significantly faster than that of the ongoing pyloric rhythm without MCN1 stimulation $(0.47 \pm 0.26 \mathrm{~Hz} ; p<0.001 ; n=29)$. Similarly, the LP, IC, and VD neurons all showed significant decreases in their activity when MCN1 was stimulated during Spantide I superfusion $(p<0.001 ; n=29)$ (Figs. 3, 4). All of these neurons, however, remained more active than without any MCN1 stimulation (Fig. 4). Without MCN1 stimulation, Spantide I did not alter either ongoing 


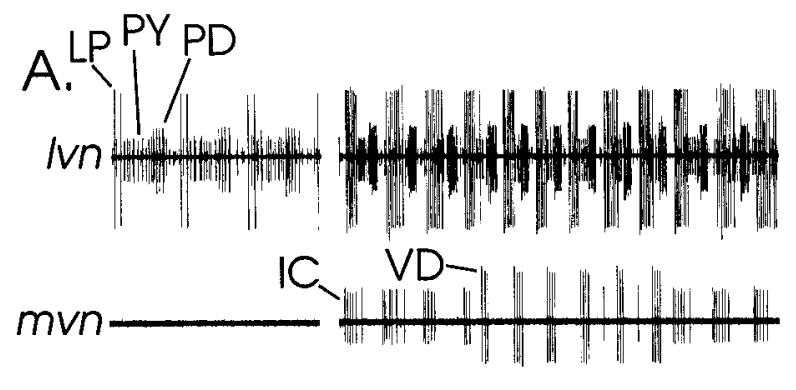

MCN1 Stim. $(20 \mathrm{~Hz})$
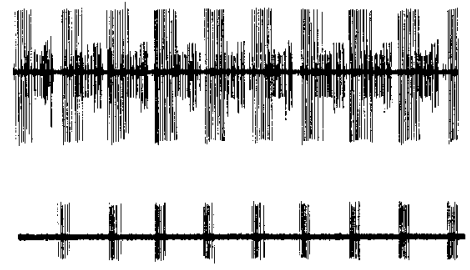

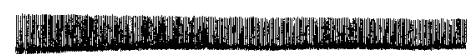

MPN $(20 \mathrm{~Hz})$

MPN: $30 \mathrm{mV}$
Figure 2. The modulatory neurons MCN1 and MPN elicit distinct pyloric rhythms. $A$ Extracellular recordings of the pyloric rhythm response to comparable stimulation of MCN1 and MPN. B, The pyloric cycle frequency and the activity level of several pyloric neurons are significantly enhanced by stimulation of either MCN1 or MPN, relative to ongoing pyloric rhythms during saline superfusion in the absence of stimulation. Additionally, there are significant differences in each of the analyzed parameters during MCN1 versus MPN stimulation. Each bar represents the mean \pm SD for the indicated parameter. MCN1 stimulations: $n=44$ MPN stimulations: $n=17$. Comparison between MCN1 and saline: ${ }^{*} p \leq 0.05$. MPN is significantly different from both saline alone and MCN1 stimulation: $\triangle p \leq 0.05$.

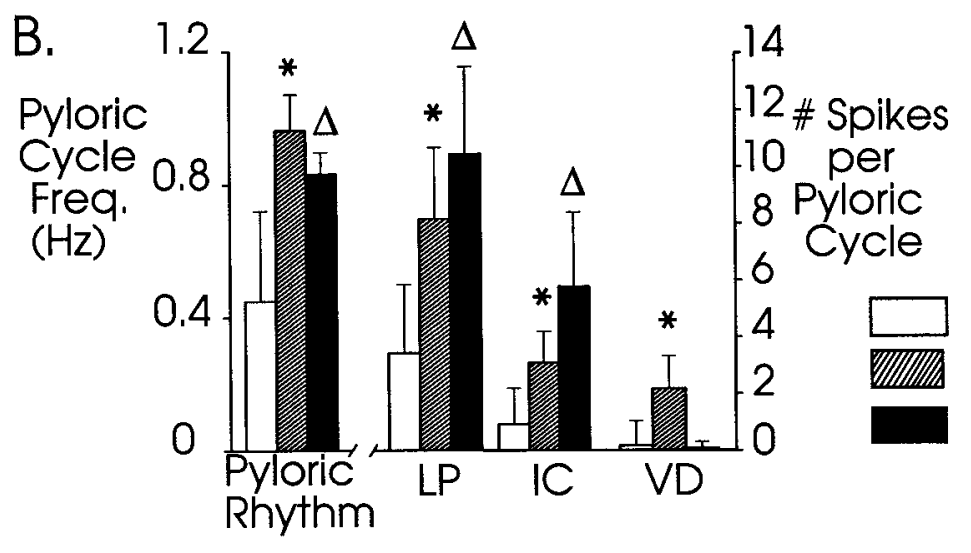

Saline

MCN1 Stim. MPN Stim.
Saline Saline

Spantide

ND

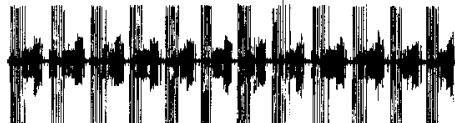

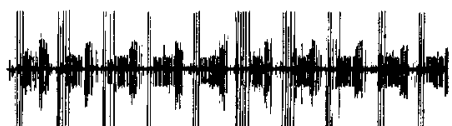
mvn 16<smiles>[CH]1CCCC1</smiles>
$\longrightarrow$

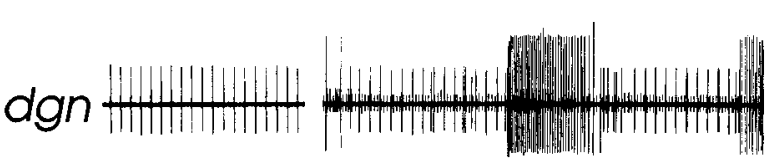
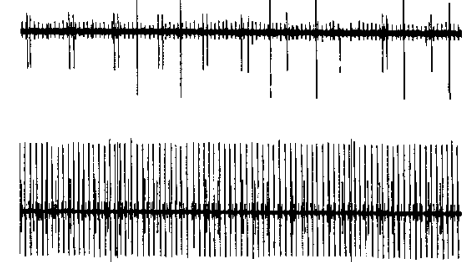

Saline Wash

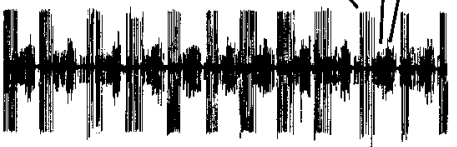
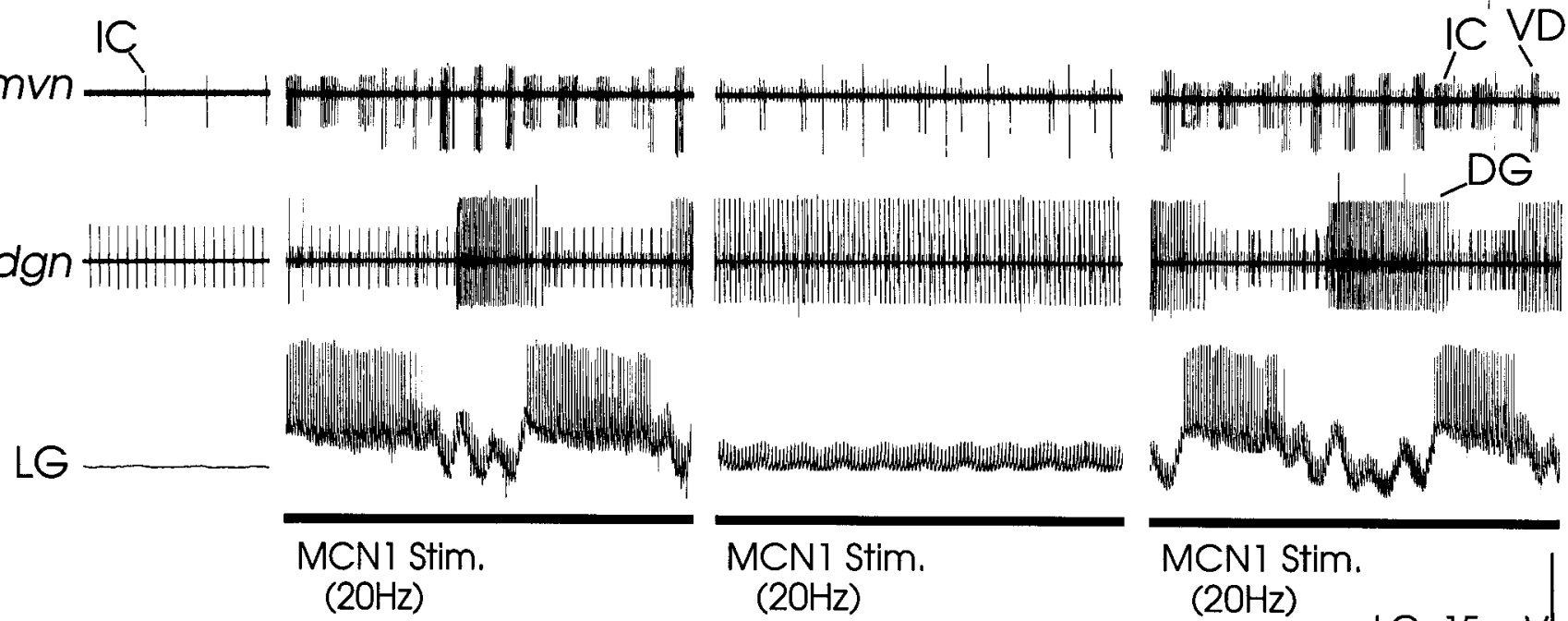

Why

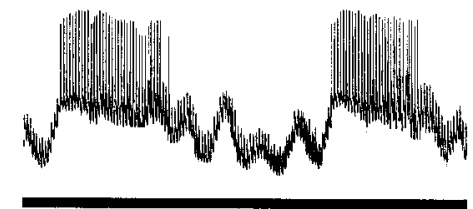

MCN1 Stim. $(2 \mathrm{OHz})$

\section{MCN1 Stim.} $(2 \mathrm{OHz})$ 


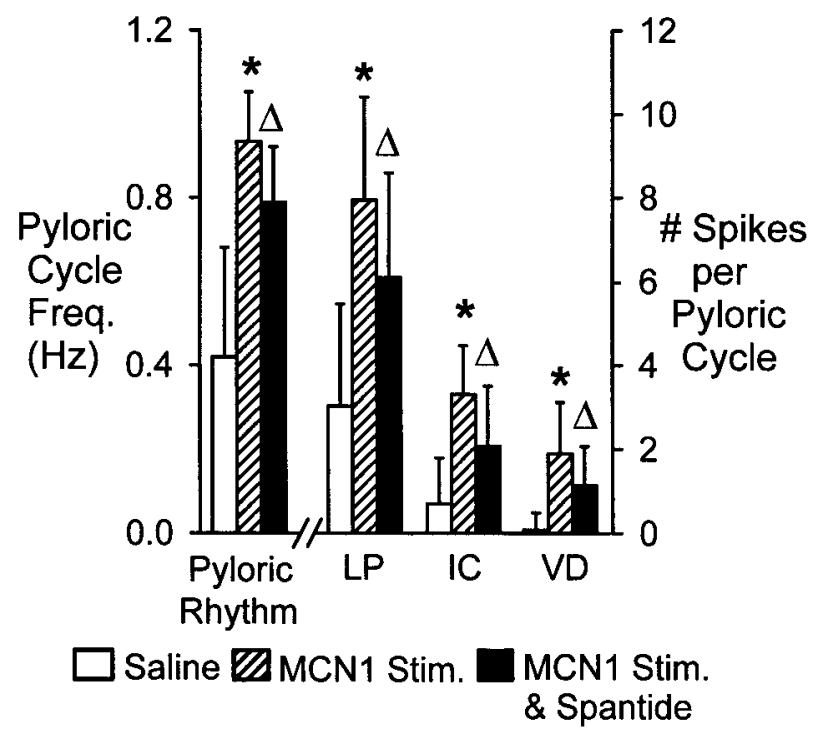

Figure 4. Quantitative comparison of pyloric rhythm parameters during tonic stimulation of MCN1 before and during Spantide I application $(2-5 \times$ $\left.10^{-5} \mathrm{M}\right)$. The pyloric cycle frequency was significantly increased when MCN1 was stimulated, whether or not Spantide I was present. However, MCN1 stimulation elicited a significantly faster cycle frequency during saline superfusion than when Spantide I was applied. The same results pertained to the activity level of at least three pyloric neurons, including the lateral pyloric $(L P)$, inferior cardiac $(I C)$, and ventricular dilator $(V D)$ neurons. Significant difference from saline control indicated by $*$ ( $p \leq$ $0.001 ; n=29)$. Significant difference from saline control and MCN1 stimulation in saline indicated by $\triangle(p \leq 0.001 ; n=29)$.

pyloric rhythm cycle frequency or the activity level of individual pyloric neurons ( $t$ test, $n=29, p>0.05$ ).

In the experiments described above, it was difficult to determine the immediate cause of the changes in these rhythms during Spantide I application because the MCN1-elicited gastric mill and pyloric rhythms also influence one another via synaptic pathways within the STG (Bartos and Nusbaum, 1997; Bartos et al., 1999). Additionally, several STG neurons participate in both of these rhythms (e.g., IC and VD neurons; Fig. 1C). The LG neuron, whose activation by MCN1 is suppressed by Spantide I, is the gastric mill neuron that regulates the actions of MCN1 on the pyloric circuit, via its presynaptic inhibition of MCN1 (Coleman and Nusbaum, 1994; Bartos and Nusbaum, 1997). Therefore, we aimed to determine whether the reduced response of the pyloric circuit to MCN1 stimulation during Spantide I superfusion was actually a secondary consequence of the elimination of the gastric mill rhythm under these conditions. To this end, we compared the pyloric system response to MCN1 stimulation with and without Spantide I present during times when LG neuron activity was suppressed by hyperpolarizing current injection.

As reported previously (Bartos and Nusbaum, 1997), the pyloric rhythm was still excited by MCN1 stimulation when the LG neuron was inactivated by hyperpolarizing current injection. This excitation was stronger in normal saline than during Spantide I superfusion (Fig. 5). With Spantide I present and LG neuron activity suppressed, MCN1 stimulation elicited a pyloric rhythm that was significantly slower than the comparable stimulation in normal saline $(p<0.02 ; n=22)$, but still significantly faster than the spontaneously active pyloric rhythm without MCN1 stimulation $(p<0.001 ; n=22)$ (Fig. $5 B)$. This result was consistent with the effects of Spantide I seen when LG neuron activity was not suppressed (Fig. 4). The same results were obtained with respect to changes in pyloric neuron activity levels. With LG neuron activity eliminated, MCN1 stimulation in normal saline increased the activity of the LP, IC, and VD neurons (Fig. 5B). When Spantide I was added to the bath, MCN1 stimulation still significantly increased the activity of these three neurons relative to their prestimulation activity levels, but to a lesser degree than in normal saline $(p<0.02 ; n=22)$ (Fig. $5 B)$. Thus, the reduced level of excitation provided by MCN1 to the pyloric system during pharmacological block of the actions of CabTRP Ia are independent of the MCN1 actions on the gastric mill circuit.

\section{Specificity and effectiveness of Spantide I block of CabTRP la actions}

The gastric mill and pyloric neurons that exhibit reduced responses to MCN1 stimulation with Spantide I present are also among the subset of STG neurons that are excited during CabTRP Ia application (Christie et al., 1997b) (D. E. Wood, A. E. Christie, W. Stein, and M. P. Nusbaum, unpublished observations). Moreover, Spantide I appears to selectively block only the CabTRP Ia component of the MCN1 actions in the STG. For example, at Spantide I concentrations $\left(10^{-4} \mathrm{M}\right)$ that eliminate the actions of bathapplied CabTRP Ia $\left(10^{-6} \mathrm{M}\right)$ on the STG, there is no change in the pyloric rhythm response to proctolin $\left(10^{-6} \mathrm{M}\right)$ superfusion (Christie et al., 1997a). Proctolin and GABA are cotransmitters of CabTRP Ia in MCN1 (Blitz et al., 1999). Additionally, Spantide I $\left(2-5 \times 10^{-5} \mathrm{M}\right)$ did not interfere with the actions of proctolin and GABA on pyloric neurons when these transmitters were released from MPN (Fig. 6). Specifically, MPN stimulation enhanced the pyloric cycle frequency and the activity of individual pyloric neurons to the same extent, relative to prestimulation levels, whether or not Spantide I was present $(p<0.001 ; n=8)$ (Fig. $6 B$ ). This included excitation of those STG neurons (LP, IC, and VD neurons) that showed decreased responsiveness to MCN1 activation with Spantide I present.

We also tested whether there were nonspecific effects of Spantide I on the gastric mill circuit. This was done by examining the actions of Spantide I on a gastric mill rhythm that does not involve the participation of MCN1. We elicited this gastric mill rhythm via extracellular stimulation of the dpon, which activates a sensory pathway that projects through this nerve to the CoGs and STG (Blitz et al., 1998; Beenhakker et al., 2000) (Fig. 1A). Stimulating this pathway for 2-3 min activated a gastric mill rhythm that persisted for an additional 5-10 min. In these experiments, we transected both ions to prevent any influence of MCN1 on the STG. The gastric mill rhythm elicited by dpon stimulation had similarities and differences to that elicited by selective stimulation of MCN1. One similarity that is evident in Figure 7 is that both rhythms included rhythmic alternating bursting between the LG and DG neurons. One distinction between these rhythms is that the gastric mill (GM) neurons generated regular bursting activity only during the dpon-elicited rhythm (Fig. 7). Another difference, not shown in Figure 7, was that IC neuron activity was eliminated during each LG neuron burst only in the dpon-elicited rhythm. Consistent with our earlier experiments (Fig. 3), we were not able to elicit the gastric mill rhythm by stimulating MCN1 during Spantide I $\left(10^{-5} \mathrm{M}\right)$ superfusion (Fig. $\left.7 A\right)$. In contrast, in these same preparations during Spantide I superfusion, the gastric mill rhythm was still readily elicited by dpon stimulation (Fig. $7 B)(n=$ 5 of 5 preparations). This included rhythmic bursting in all the same gastric mill neurons, including the LG, DG, and GM neurons (Fig. 7B).

We next aimed to verify that Spantide I completely eliminated the gastric mill and pyloric responses to neurally released CabTRP Ia. To this end, we attempted to strengthen the actions of neurally released CabTRP Ia within the STG by increasing both its local concentration and the duration of its presence, by preventing its enzymatic degradation. Many tachykinins are cleaved and inactivated in the extracellular space by neutral endopeptidase-24.11 (NEP), and NEP activity is effectively inhibited by phosphoramidon in both vertebrates and invertebrates (Turner et al., 1987; Roques et al., 1993; Saleh et al., 1996; Zappulla et al., 1999).

We first examined whether phosphoramidon $\left(10^{-5} \mathrm{M}\right)$ superfusion would selectively enhance the actions of applied CabTRP Ia in the crab STG. We found that this endopeptidase inhibitor $\left(10^{-5} \mathrm{M}\right)$ did indeed reliably enhance the actions of focally applied CabTRP Ia (pipette concentration, $10^{-4} \mathrm{M}$ ). For example, we determined 
Figure 5. The MCN1-elicited pyloric rhythm is still altered when CabTRP Ia actions are blocked with Spantide I during suppression of the gastric mill rhythm. $A$, When the gastric mill rhythm was suppressed by maintained hyperpolarization of the LG neuron (note the lack of gastric mill-timed activity in the IC and VD neurons), the pyloric rhythm (lvn, $m v n$ ) was still enhanced by MCN1 stimulation during superfusion of saline either alone or with Spantide I $\left(2 \times 10^{-5} \mathrm{M}\right)$. However, the MCN1-elicited pyloric rhythm is slower and weaker during the latter condition. $B$, Quantitative comparison of several pyloric rhythm parameters under these conditions shows that the pyloric cycle frequency and activity level of the LP, IC, and VD neurons are all enhanced by MCN1 stimulation. However, all of these parameters are significantly reduced during Spantide I application. Significant difference from saline control indicated by * $(p \leq 0.05 ; n=22)$. Significant difference from saline control and MCN1 activation with LG hyperpolarized in normal saline is indicated by $\triangle(p \leq$ $0.05 ; n=22$ ).

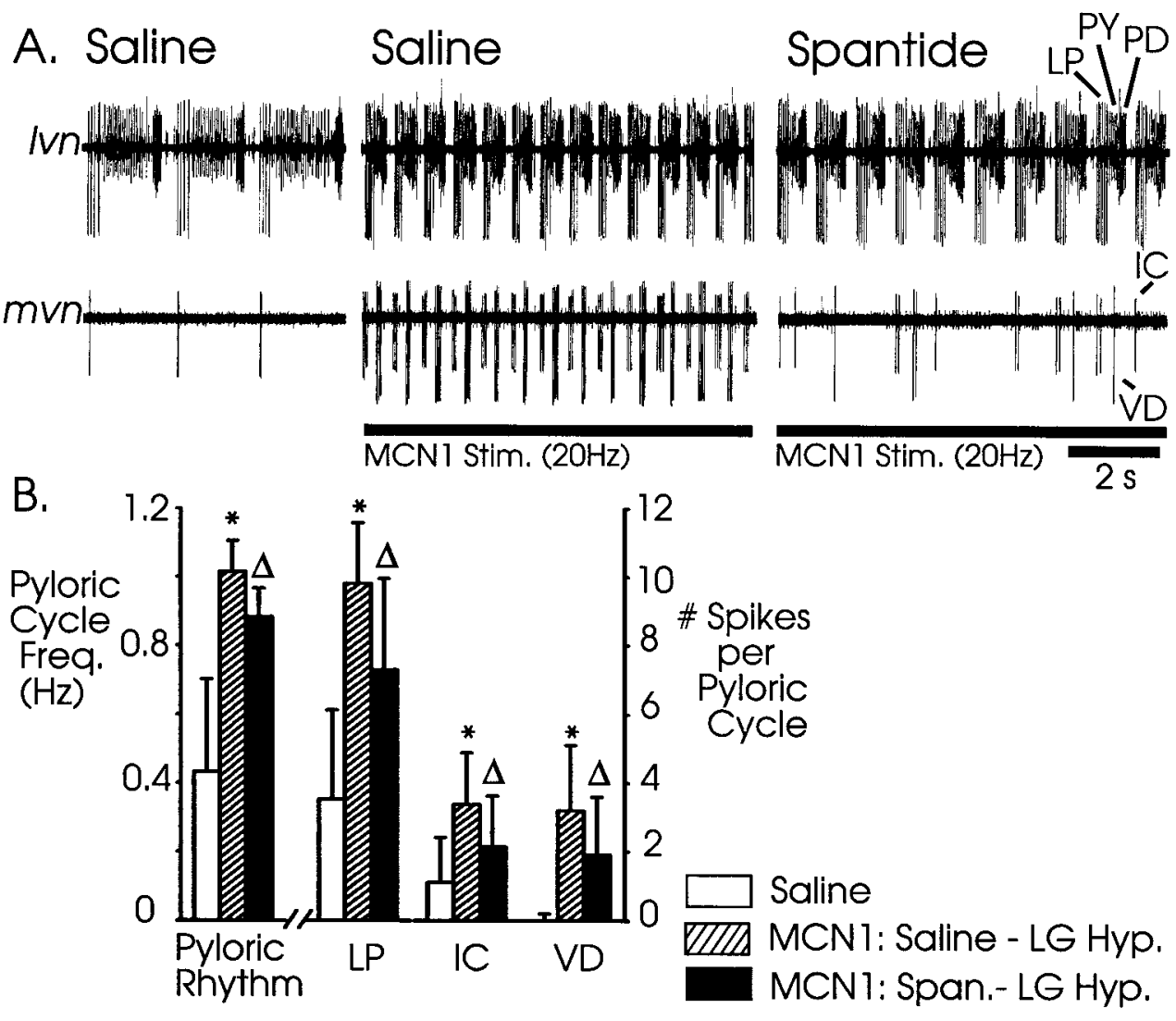

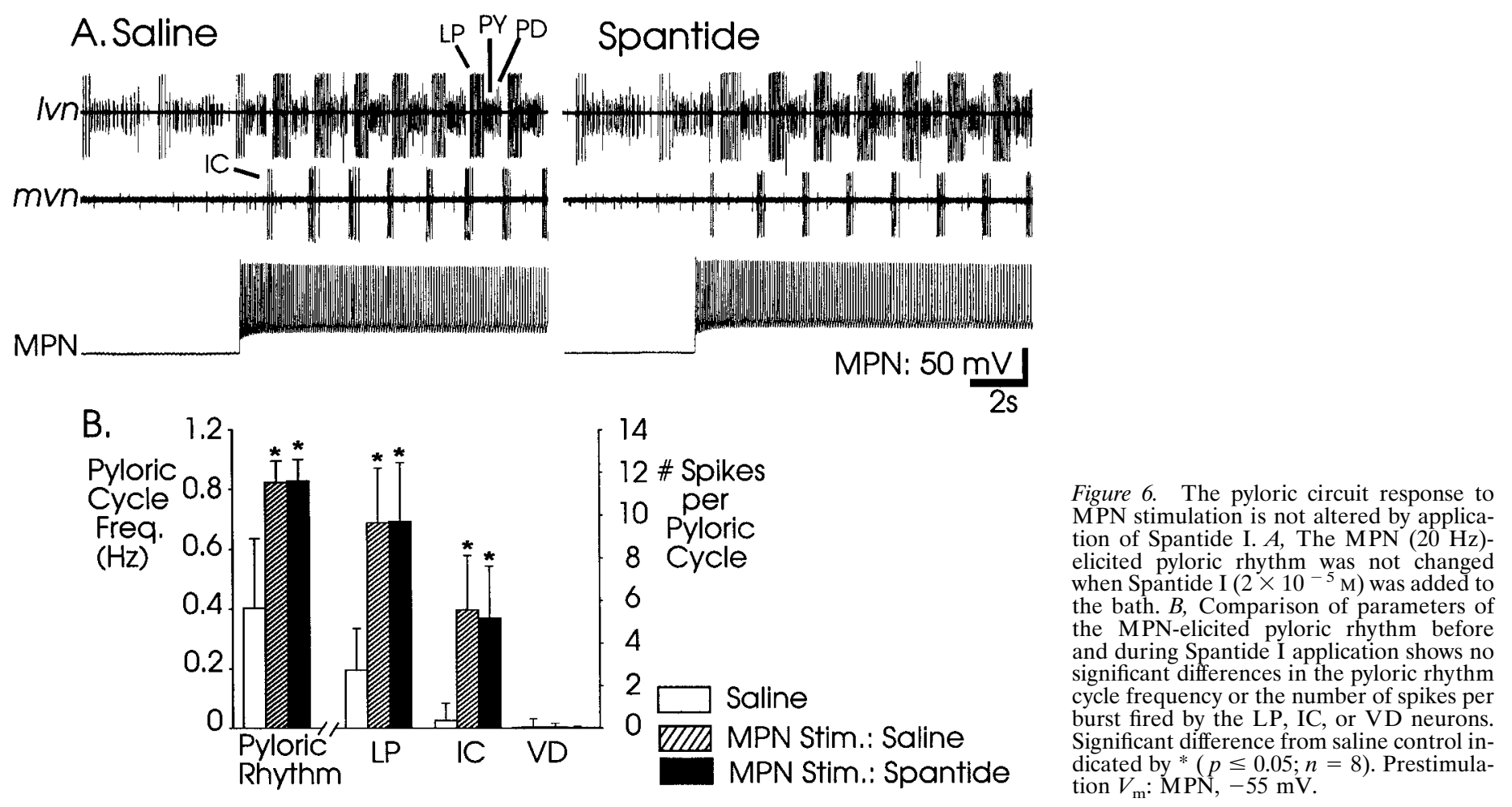

the time required for each measured parameter to return to preapplication levels after the end of a standard duration $(2 \mathrm{sec})$ and intensity (6 PSI) presentation of this neuropeptide. As shown in Figure 8, the LG neuron response to applied CabTRP Ia was intensified and prolonged in the presence of phosphoramidon $(p<$ $0.01 ; n=8)$. So too was the pyloric cycle frequency, which was increased by CabTRP Ia application for $64.8 \pm 40.4 \mathrm{sec}$ during saline superfusion and for $136.6 \pm 83.8 \mathrm{sec}$ with phosphoramidon present ( $p<0.05 ; n=7$ ). We showed previously that there is also an increased pyloric rhythm response to both applied and neurally released proctolin after blocking extracellular aminopeptidase activity in the STG (Coleman et al., 1994; Nusbaum and Wood, 1999). Because proctolin is a cotransmitter of CabTRP Ia within MCN1, we also examined whether phosphoramidon altered the STG response to proctolin application. There were no changes in the pyloric rhythm response to focally applied proctolin (pipette 

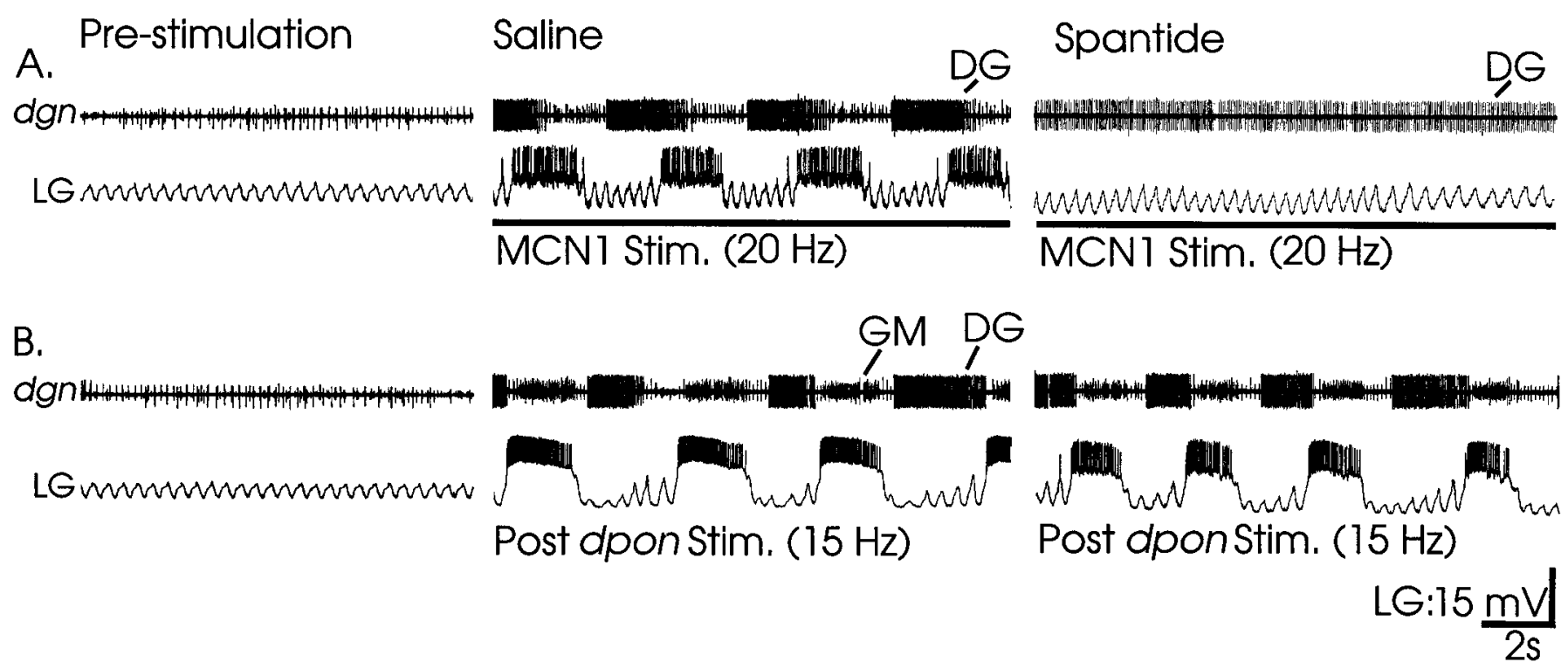

Figure 7. The tachykinin receptor blocker Spantide I selectively blocks gastric mill rhythm activation by MCN1. $A$, Tonic stimulation of MCN1 elicited the gastric mill rhythm during saline superfusion but not during Spantide I application $\left(10^{-5} \mathrm{M}\right)$. The gastric mill rhythm is represented by rhythmic alternating impulse bursts in the LG and DG neurons. The two nonrhythmic units recorded on the $d g n$ are the AGR sensory neuron and the gastric mill $(G M)$ motor neurons. B, Stimulation of the dorsal posterior oesophageal nerve (dpon) during saline superf usion activated a different version of the gastric mill rhythm, which then persisted for $\sim 10$ min after stimulation. MCN1 did not contribute to this gastric mill rhythm because the ions were transected. This gastric mill rhythm was again activated by dpon stimulation in the presence of Spantide I $\left(10^{-5} \mathrm{M}\right)$. Note that, in contrast to the MCN1-elicited rhythm, the GM neurons ( $d g n)$ participated in the $d p o n$-elicited gastric mill rhythm. $A$ and $B$ were from the same experiment, and stimulations occurred during the same applications of Saline (middle) and Spantide I (right). In each case, dpon stimulation was performed after the effects of MCN1 stimulation subsided. Most hyperpolarized LG $V_{\mathrm{m}}$ : Prestimulation, $-64 \mathrm{mV}$; Saline, $-67 \mathrm{mV}$; Spantide, $-68 \mathrm{mV}$.

concentration, $\left.10^{-4} \mathrm{M}\right)$ during phosphoramidon superfusion $\left(10^{-5}\right.$ M) (Fig. $\left.8, p>0.05 ; n=7\right)$. The LG neuron was not directly affected by proctolin application whether or not phosphoramidon was present. However, under these conditions the LG neuron did exhibit subthreshold pyloric-timed membrane potential oscillations (Fig. $8 B$ ). These were because of proctolin excitation of the pyloric rhythm. The LG neuron receives pyloric-timed synaptic inhibition (Bartos et al., 1999). The presence of phosphoramidon itself did not alter any aspect of STG activity in the absence of either peptide application or projection neuron stimulation $(p>0.05 ; n=23)$.

Phosphoramidon $\left(10^{-5} \mathrm{M}\right)$ also enhanced the STG response to MCN1 stimulation. For example, during the MCN1-elicited gastric mill rhythm, there was an increased number of spikes per burst in the LG neuron ( $p<0.02 ; n=5)$ and an increase in the gastric mill cycle period ( $p<0.02 ; n=5$ ) (Fig. 9). DG neuron burst duration also appeared to increase during these gastric mill rhythms with phosphoramidon present (Fig. 9A), but we did not determine whether this change was a direct consequence of phosphoramidon application or an indirect result of the change in LG neuron activity. During MCN1-elicited gastric mill rhythms, the LG neuron regulates the timing and duration of DG neuron activity (Coleman and Nusbaum, 1994).

Despite the ability of phosphoramidon to increase and prolong the actions of focally applied and neurally released CabTRP Ia, the STG response to MCN1 stimulation during coapplication of phosphoramidon and Spantide I was the same as during application of Spantide I alone (Fig. 9B). For example, under both conditions the LG neuron response to MCN1 stimulation was limited to the presence of electrical EPSPs, as shown for Spantide I alone in Figure 3. There was no spiking activity elicited from the LG neuron during these stimulations. Thus, the gastric mill rhythm was never activated (5 of 5 preparations) (Fig. 9B). Similarly, the DG neuron continued to respond to MCN1 stimulation by firing tonically when phosphoramidon was coapplied with Spantide $(n=5)$. There was also no difference in the pyloric rhythm response to MCN1 stimulation when Spantide I was superfused with or without phosphoramidon $(p>0.05 ; n=5)$. The reduced effectiveness of MCN1 stimulation under both conditions was readily reversible with subsequent saline superfusion (Fig. 9B). These results are therefore consistent with the conclusion that Spantide I is effectively blocking the actions of CabTRP Ia on the gastric mill and pyloric rhythms.

\section{Different projection neurons with proctolin and GABA cotransmitters have distinct actions on the pyloric circuit}

One aspect of our working hypothesis, that CabTRP Ia was responsible for the distinct actions of MCN1 and MPN on the STG circuits, was confirmed by showing that MCN1 no longer elicited a gastric mill rhythm in the presence of Spantide I (Fig. 3). We next examined whether the same pyloric rhythm was elicited by MCN1 and MPN when Spantide I was present. To ensure a direct comparison, we injected hyperpolarizing current into the LG neuron to eliminate any residual activity occurring during MCN1 stimulation. When these two projection neurons were stimulated at comparable firing rates under these conditions, the pyloric rhythms elicited by each neuron were more similar to one another than in normal saline, but they remained distinct (Fig. 10). Specifically, the pyloric cycle frequency was now the same during MCN1 stimulation with the LG neuron hyperpolarized and Spantide I present $(0.87 \pm 0.11 \mathrm{~Hz} ; n=29)$ and during MPN stimulation with Spantide I present $(0.83 \pm 0.07 \mathrm{~Hz} ; p>0.05 ; n=17)$ (Fig. 10C). However, the activity level of the LP, IC, and VD neurons remained distinct during stimulation of these two projection neurons (Fig. 10C). The LP and IC neurons still fired significantly more action potentials per pyloric cycle during MPN stimulation ( $p \leq$ $0.05 ; n=17$ ), whereas VD neuron activity remained stronger during MCN1 stimulation ( $p \leq 0.05 ; n=17$ ). There were also differences in the intensity of firing in some pyloric neurons during MCN1 and MPN stimulation under these conditions. For example, the intraburst firing frequency of the PD and IC neurons was significantly higher during MPN than MCN1 stimulation $(p \leq$ $0.05 ; n=7$ ) (Fig. 11), although the firing rates of these neurons during MCN1 stimulation were higher than during the spontaneously cycling rhythm (Fig. 11). Although there were more LP neuron impulses per cycle when MPN was activated than during MCN1 stimulation, in these experiments there was no difference in LP neuron firing frequency under these two conditions (Fig. 11).

Direct comparison of the three-phase pyloric activity patterns 

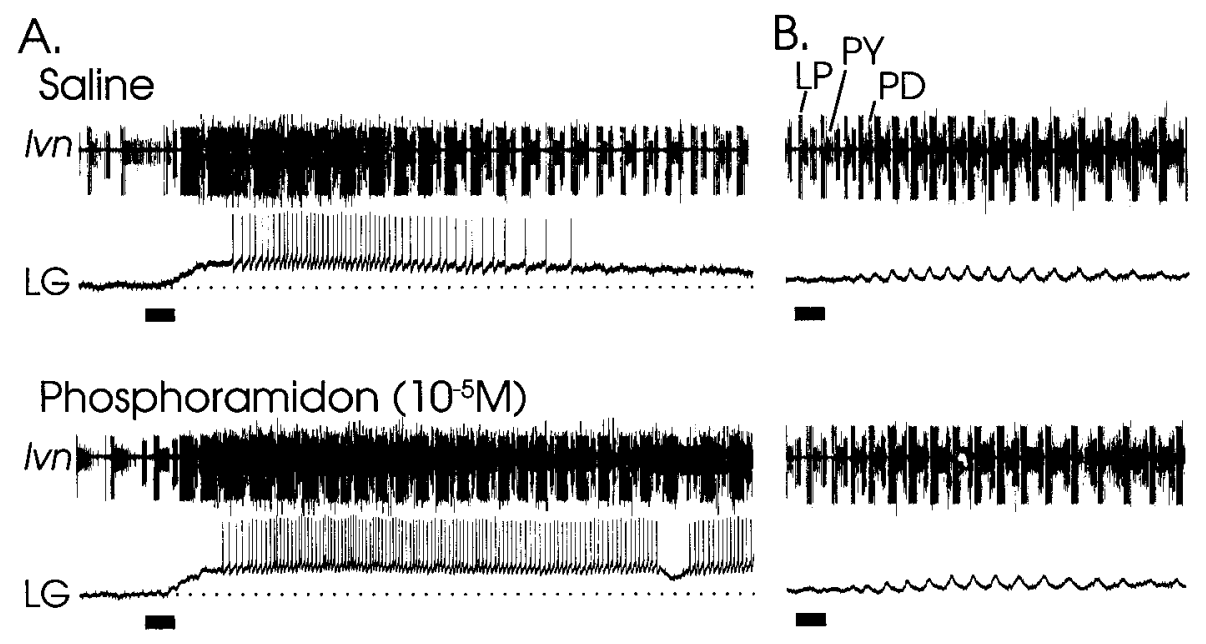

Saline Wash

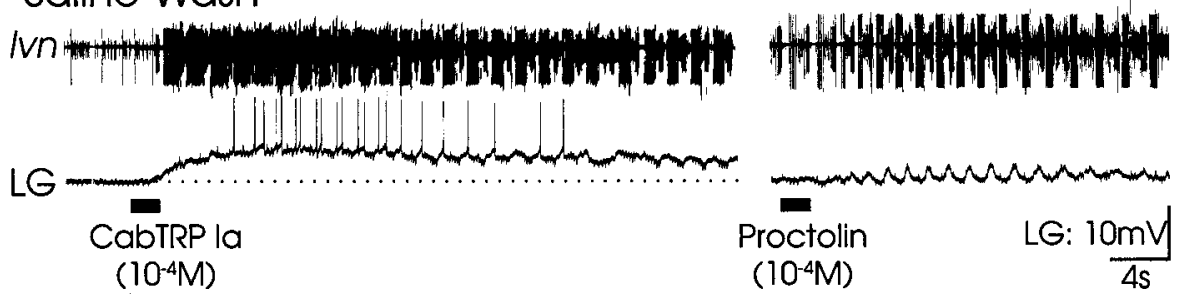

C.

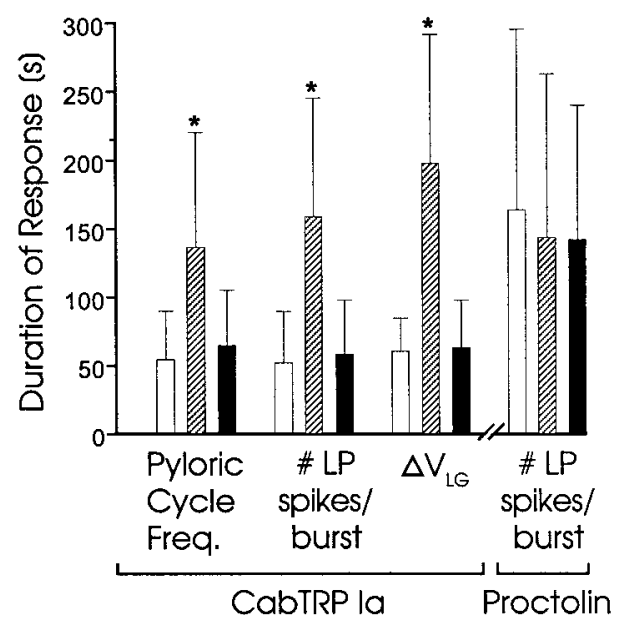

Saline

Phosphoramidon $\left(10^{-5} \mathrm{M}\right)$ Saline Wash

Figure 8. The endopeptidase inhibitor phosphoramidon selectively enhances the actions of focally applied CabTRP Ia on the STG. $A$, Focal application of CabTRP Ia $\left(10^{-4} \mathrm{M}\right.$ in puffer pipette, 6 PSI) onto the desheathed STG neuropil excited the LG neuron and enhanced the pyloric rhythm (lvn). The response of both the pyloric neurons and the LG neuron to CabTRP Ia was increased in strength and duration during superfusion of phosphoramidon $\left(10^{-5} \mathrm{M}\right)$, in a reversible manner. $B$, Focal application of proctolin $\left(10^{-4} \mathrm{M}\right.$ in puffer pipette, 6 PSI) onto the STG neuropil excited the pyloric rhythm (lvn) but did not excite the LG neuron. Note that there was no sustained depolarizing response in the LG neuron. The onset of the pyloric-timed subthreshold oscillations in the LG neuron after proctolin application was an indirect result of proctolin excitation of the pyloric circuit. There was no change in the response of either the pyloric neurons or the LG neuron to proctolin application during phosphoramidon (10 $\left.{ }^{-5} \mathrm{M}\right)$ superfusion. Most hyperpolarized LG $V_{\mathrm{m}}:-62 \mathrm{mV}$. C, Superfusion of phosphoramidon significantly prolonged the excitatory actions of focally applied (2 sec, 6 PSI) CabTRP Ia, but not proctolin, on the pyloric rhythm and the LG neuron. The asterisks indicate that, relative to pre and postapplication saline controls, phosphoramidon significantly increased the duration of CabTRP Ia action on the pyloric cycle frequency $(p<0.05 ; n=7)$, the number of LP spikes/pyloric-timed burst $(p<0.01 ; n=7)$, and the depolarization of the LG neuron $(p<0.01 ; n=8)$. In contrast, phosphoramidon neither enhanced nor prolonged the pyloric rhythm response to proctolin application $(p>0.05 ; n=7)$. Duration of response of all three parameters was measured from the end of the peptide application to the return of that parameter to prepeptide application levels.

produced by MPN and MCN1, with CabTRP Ia actions blocked and LG neuron activity suppressed, revealed that these patterns were only equivalent for the first phase of the pattern (Fig. 12). During this phase, the coactive PD and LPG motor neurons fired their impulse bursts for the same fraction of the cycle (duty cycle) during stimulation of either projection neuron. In contrast, the duty cycles of all of the other pyloric motor neurons were different during these two pyloric rhythms ( $p \leq 0.05 ; n=6)$. Three of these neurons (IC, LP, and PY) had significantly longer duty cycles during MPN stimulation, whereas the fourth motor neuron (VD) had a longer duty cycle during MCN1 stimulation. There was no VD neuron activity during MPN stimulation (Figs. $1 C, 2,6,9)$. The difference in the IC, LP, and PY neuron duty cycles resulted from significant phase delays in their burst onset during MCN1 stimulation (Fig. 12).

\section{DISCUSSION}

In this study we found that cotransmitter complement is one means by which projection neurons elicit distinct motor patterns from the same multifunctional network. Our results show that the presence of the peptide cotransmitter CabTRP Ia in the modulatory projection neuron MCN1 contributes to the distinct motor patterns elicited from the STG network by MCN1 and MPN. MCN1 and MPN share the cotransmitters GABA and proctolin, but only MCN1 contains CabTRP Ia (Fig. 1B) (Blitz et al., 1999). With CabTRP Ia actions on the STG blocked by Spantide I, the STG response to $\mathrm{MCN} 1$ activation more closely resembled its response to MPN activity, but differences remained.

The STG response to MCN1 and MPN became more similar in several ways with the actions of CabTRP Ia blocked. Most dramatically, the presence of Spantide I eliminated the activation of the gastric mill rhythm by MCN1, so that in this condition MCN1 only modified the pyloric rhythm. MPN stimulation never activates the gastric mill rhythm (Blitz and Nusbaum, 1997). The MPN- and MCN1-elicited pyloric rhythms also became more similar with Spantide I present as the pyloric cycle frequency became equivalent during stimulation of either neuron. However, the activity levels of many pyloric neurons and the pyloric neuron phase relationships that help define the motor pattern remained distinct. Different modulatory neurons with a common peptide transmitter, myomodulin, also have distinct actions on the feeding motor pattern in Aplysia (Hurwitz et al., 1999; Xin et al., 1999). However, it is not known whether the different actions of these neurons result from different actions of myomodulin or as yet unidentified cotransmitters.

The fact that the MPN- and MCN1-elicited pyloric rhythms remained different when the actions of CabTRP Ia were blocked suggest that the actions of proctolin and/or GABA are different when released into the STG by MPN and MCN1. With respect to proctolin, these two projection neurons may differ in the amount that they release, the local concentration of released proctolin at the proctolin receptors, and/or in the access of released proctolin 

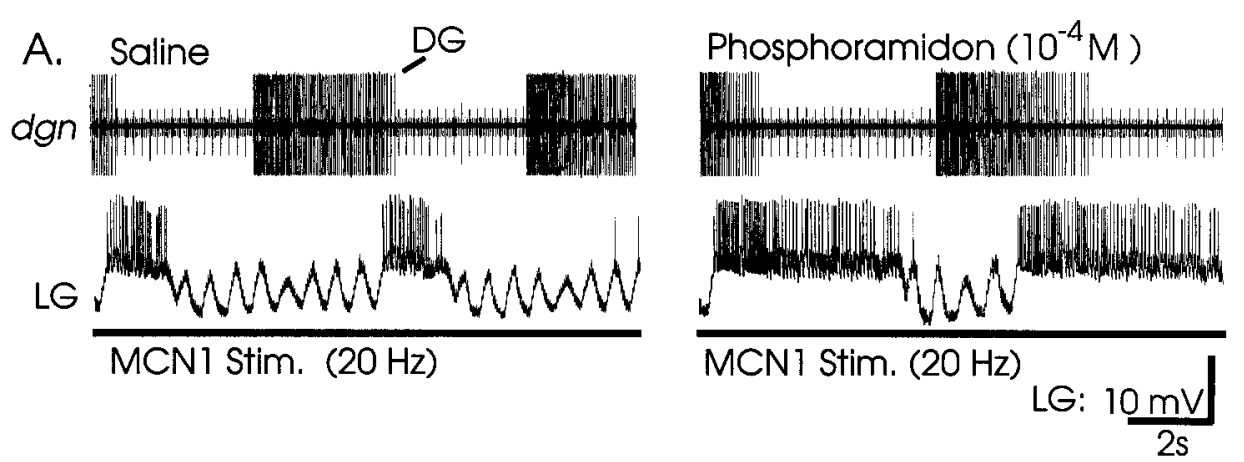

B.

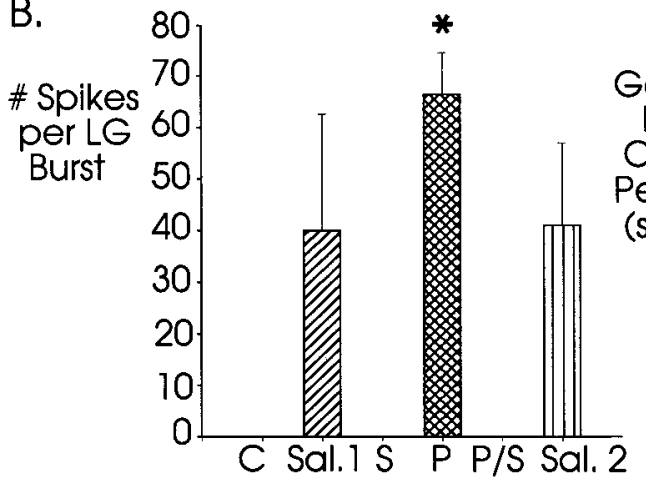

MCN1 Stim.
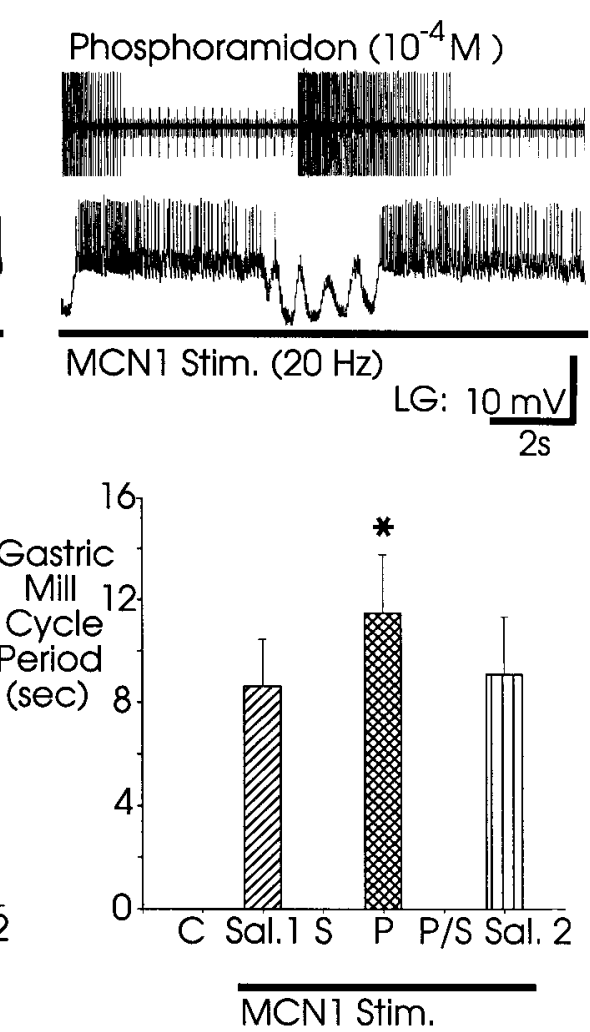

Figure 9. Phosphoramidon does not enable neurally released CabTRP Ia to overcome the blocking actions of Spantide I. $A$, The presence of the peptidase inhibitor phosphoramidon $\left(10^{-5} \mathrm{M}\right)$ enhanced the LG neuron response to MCN1 stimulation. Note the considerable increase in both the number of action potentials and the burst duration in the LG neuron when MCN1 was stimulated in the presence of phosphoramidon. As in Figure 3, the larger tonically active unit is the AGR neuron, whereas the smaller tonic unit represents stimulus artifacts from ion stimulation. Most hyperpolarized LG $V_{\mathrm{m}}:-68 \mathrm{mV}$. $B$, Phosphoramidon did not rescue the $\mathrm{LG}$ neuron response to MCN1 stimulation in the presence of Spantide I. Activation of MCN1 $(20 \mathrm{~Hz})$ readily elicited the gastric mill rhythm during saline superfusion $(\mathrm{Sal}$.) or in the presence of phosphoramidon $\left(P ; 10^{-5} \mathrm{M}\right)$. However, during phosphoramidon superfusion, both LG neuron activity (number of LG spikes per burst) and the gastric mill cycle period were significantly increased relative to $\mathrm{MCN} 1$ stimulation during saline superfusion (both parameters: * represents $p<0.02 ; n=5$ ). In contrast, there was neither LG neuron activity nor a gastric mill rhythm elicited when MCN1 was stimulated in the presence of Spantide I $\left(S ; 2-5 \times 10^{-5} \mathrm{M}\right)$, with or without coapplication of phosphoramidon $\left(10^{-5}\right.$ M) $(n=5)$. Neither the LG neuron nor the gastric mill rhythm were active without MCN1 stimulation during saline superfusion. $C$, Pre-MCN1 stimulation controls during saline superfusion; Sal. 1, saline superfusion before Spantide I application; $S$, Spantide I application; $P$, phosphoramidon application; $P / S$, phosphoramidon and Spantide I coapplication; Sal. 2, saline superfusion after washout from $\mathrm{P} / \mathrm{S}$. to all proctolin receptors. There is precedence in the Aplysia neuromuscular system for different identified neurons releasing different amounts of the same neuropeptide at the same firing frequency (Vilim et al., 2000). Any differences in levels of released proctolin could produce different pyloric rhythms, insofar as concentration-dependent modulation of the pyloric rhythm occurs during bath application of several neuromodulators (Flamm and Harris-Warrick, 1986; Weimann et al., 1997; Ayali and HarrisWarrick, 1999). Any differences in local proctolin levels are likely to result in part from the proctolinergic actions of MPN and MCN1 being sculpted differently by extracellular peptidase activity (Nusbaum and Wood, 1999). Extracellular aminopeptidase activity in the STG degrades and inactivates proctolin (Coleman et al., 1994). Peptidase activity limits the actions of neurally released peptides in many systems (Squire et al., 1991; Rose et al., 1996; Saleh et al., 1996; Zappulla et al., 1999).

These two projection neurons may also make GABAergic synapses on different target neurons or have qualitatively distinct actions on the same (or different) target neurons. Focally applied GABA has both excitatory and inhibitory actions in the crab STG, including having both actions on many STG neurons (Swensen et al., 2000). It also remains possible that the persisting distinct actions of these projection neurons when the CabTRP Ia receptor is blocked results from one or both of them containing another cotransmitter. It seems unlikely that an additional transmitter participates in the MPN modulation of the pyloric rhythm because these actions are mimicked by proctolin superfusion (Nusbaum and Marder, 1989b). Thus far, each neuron is known not to contain a number of transmitters that have been localized to other STG inputs (Blitz et al., 1999).

There are no available pharmacological tools for determining the extent to which the different pyloric rhythms elicited by MCN1 and MPN in the presence of Spantide I result from differences in proctolin and/or GABA actions. There are no effective proctolin receptor blockers available (M. P. Nusbaum, unpublished observations), and the available GABA antagonists do not effectively block all GABA actions in the STG (Swensen et al., 2000).

Aside from the possibility of additional chemical cotransmitters, there is another form of synaptic transmission that is used differ- ently by MPN and MCN1. Specifically, electrical transmission plays an important role in enabling MCN1 to elicit the gastric mill rhythm (Coleman et al., 1995; Nadim et al., 1998), and MCN1 is also electrically coupled to several pyloric neurons (Coleman, 1995; Norris et al., 1995). There is no evidence for electrical transmission involving MPN, and it is clear that at least some of these electrical synapses are unique to MCN1 because MPN has no actions whatsoever on at least some of the gastric mill neurons to which MCN1 is electrically coupled (Blitz and Nusbaum, 1997).

MCN1 and MPN appear to share many neuronal targets within the STG. However, two targets that are influenced only by MCN1 are the LG and DG neurons of the gastric mill system (Coleman and Nusbaum, 1994; Coleman et al., 1995; Blitz and Nusbaum, 1997). Neither of these neurons are responsive to proctolin application, but both show reduced responses to MCN1 stimulation in the presence of Spantide I. In Spantide I, all but the electrical EPSPs are eliminated in the LG neuron response to MCN1 stimulation, suggesting that MCN1 only uses CabTRP Ia to influence this neuron. In contrast, the DG neuron response to MCN1 with Spantide I present is altered from rhythmic oscillatory activity to tonic firing, suggesting that MCN1 uses both CabTRP Ia and GABA to influence this neuron.

There is also a functional compartmentalization of MPN cotransmitter actions. Although there is no evidence within the STG regarding the use of the MPN cotransmitters on individual targets, MPN uses only GABA to influence some projection neurons in the CoGs (Blitz and Nusbaum, 1999). Similarly, in the neuroendocrine bag cell system of Aplysia, the coreleased $\alpha$ bag cell peptide and egg-laying hormone do not influence all of the same target neurons (Mayeri et al., 1985; Sigvardt et al., 1986).

Another possible explanation for the continued differences in the STG response to MCN1 and MPN stimulation is that Spantide I did not completely block the actions of neurally released CabTRP Ia. This possibility, however, seems unlikely because increasing the effectiveness of CabTRP Ia, by using a peptidase inhibitor that enhanced the actions of this peptide, did not rescue any of the MCN1 actions that were suppressed by Spantide I.

If the STG response to MCN1 and MPN during Spantide I application does indeed remain different because of their distinct 


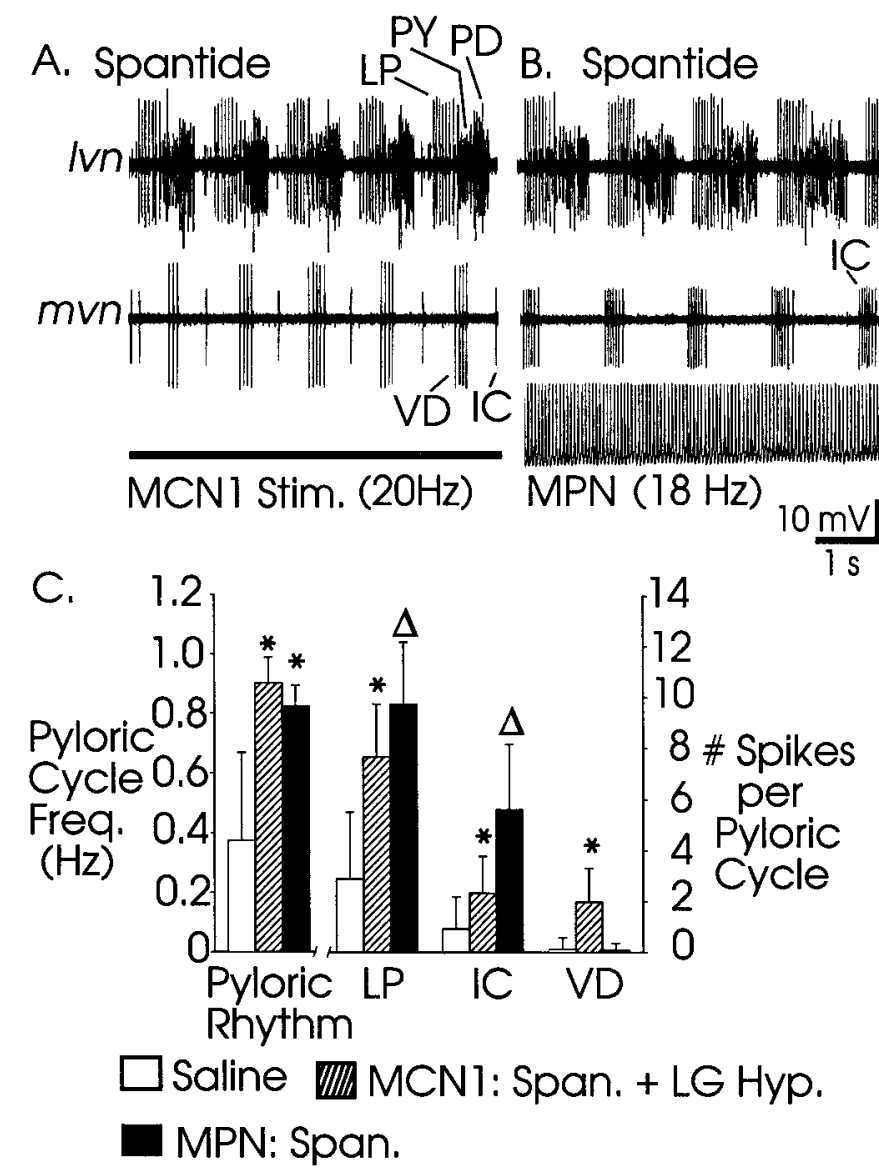

Figure 10. The MCN1- and MPN-elicited pyloric rhythms remain distinct during Spantide I $\left(2 \times 10^{-5} \mathrm{M}\right)$ application. $A$, An example of the MCN1elicited pyloric rhythm during Spantide I application. LG neuron activity was suppressed with hyperpolarizing current injection. $B$, An example of the MPN-elicited pyloric rhythm from the same preparation shown in $A$. LG neuron activity was suppressed as in $A$. Note the differences between this rhythm and the MCN1-elicited rhythm in $A$. For example, the VD neuron was only active during the MCN1-elicited pyloric rhythm, whereas the IC neuron was more active during the MPN-elicited rhythm. $V_{\mathrm{m}}$ : MPN, $-55 \mathrm{mV}$. C, Quantitative comparison of several parameters from these two pyloric rhythms reveals there is no difference in the pyloric cycle frequency, but that differences persist in the activity levels of the LP, IC, and VD neurons. The IC and LP neurons produced more spikes per burst during MPN stimulation, whereas the VD neuron was active only during MCN1 stimulation. Significant difference from saline control indicated by $*(p \leq$ $0.05 ; n=20)$. Significant difference from saline control and MCN1 stimulation indicated by $\triangle(p \leq 0.05 ; n=17)$.

use of proctolin and/or GABA, this would provide further support for the hypothesis that the use of distinct cotransmitters is only one of several strategies used by different modulatory projection neurons to elicit distinct motor patterns from the same network. In this particular case, one additional strategy involves the use of electrical transmission only by MCN1 to influence the STG circuits. There is also a major role played by the pattern of transmitter release. There is a rhythmic release of the MCN1 cotransmitters, which results from rhythmic presynaptic inhibition of the STG terminals of MCN1 by a gastric mill neuron (LG neuron; Fig. $1 B$ ) (Coleman and Nusbaum, 1994; Coleman et al., 1995; Bartos and Nusbaum, 1997). In contrast, the modulatory actions of MPN appear to result from its tonic release of neurotransmitters. There is no indication of rhythmic presynaptic control of the STG terminals of MPN. This is consistent with the fact that bath applied proctolin and MPN stimulation elicit the same pyloric rhythm (Nusbaum and Marder, 1989b). Interactions between projection neurons can also contribute to motor pattern selection. For example, MPN activity prevents the activation of the gastric mill rhythm in the STG via its inhibitory actions on other projection neurons within the CoGs

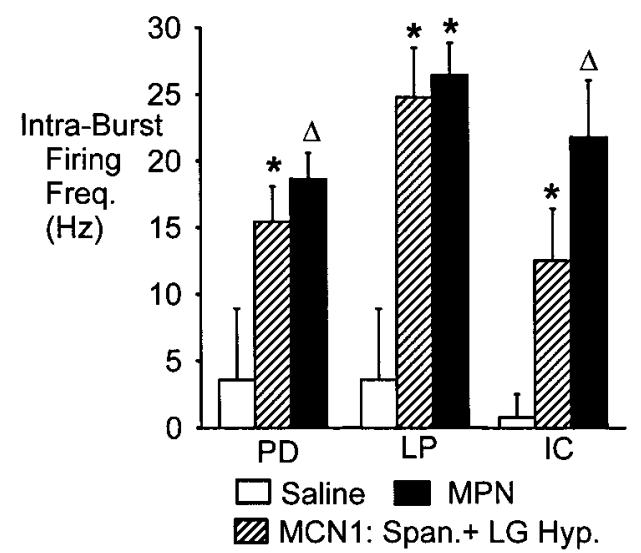

Figure 11. Intraburst firing frequency in some pyloric neurons is different during the MPN- and MCN1-elicited pyloric rhythms with Spantide I $\left(2-5 \times 10^{-5} \mathrm{M}\right)$ present and the LG neuron hyperpolarized. The PD, LP, and IC neurons exhibited increased firing intensity when MCN1 or MPN was stimulated, relative to their prestimulation values (indicated by ${ }^{*} p \leq$ $0.05 ; n=7)$. PD and IC neuron firing frequency was significantly higher during MPN than MCN1 stimulation. Significant difference during MPN stimulation, relative to saline controls and $\mathrm{MCN} 1$ activation indicated by $\triangle$ $(p \leq 0.05 ; n=7)$.

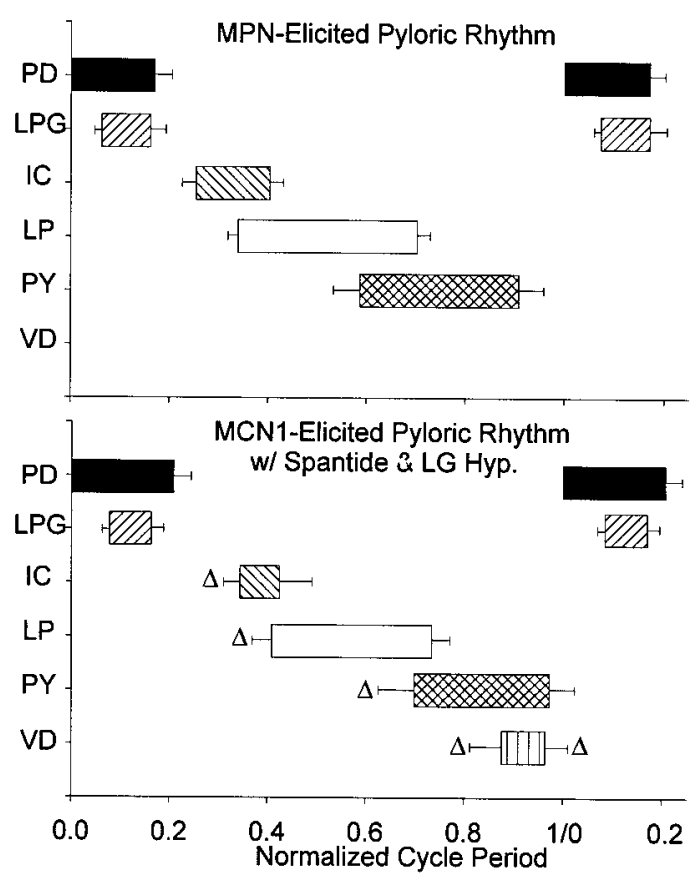

Figure 12. Distinct pyloric motor patterns were elicited by MPN and MCN1 stimulation when CabTRP Ia actions were blocked by Spantide I $\left(2-5 \times 10^{-5} \mathrm{M}\right)$. The phase relationships (the fraction of a normalized pyloric cycle during which each neuron is active) are shown as a function of the normalized pyloric cycle period. Pyloric cycle period is arbitrarily designated as beginning with burst onset in the PD neuron, and ending with the onset of the next PD burst. Top panel, Pyloric motor pattern during tonic MPN stimulation $(20 \mathrm{~Hz})$. Bottom panel, Activity pattern of the same neurons during tonic MCN1 stimulation $(20 \mathrm{~Hz})$. The phase of burst onset and offset for the LPG neuron, and offset of the PD neuron, was not significantly different between the conditions $(p>0.05 ; n=6)$. There were also no differences in the phase of burst offset of the IC, LP, and PY neurons when either projection neuron was stimulated, but the phase of burst onset for each of these neurons occurred earlier during MPN stimulation $(\triangle: p \leq 0.05 ; n=6)$. Burst onset and offsets phases for the VD neuron were not compared because VD was not active during MPN activation $(n=6$ of 6$)$.

(Blitz and Nusbaum, 1997). In conclusion, distinct cotransmitters clearly provide one means by which different modulatory projection neurons elicit distinct activity patterns from the same neuronal network. However, motor pattern selection from a multifunctional 
network is a more complex process that also involves a constellation of additional strategies.

\section{REFERENCES}

Agnati LF, Zoli M, Stromberg I, Fuxe K (1995) Intercellular communication in the brain: wiring versus volume transmission. Neuroscience 69:711-726.

Ayali A, Harris-Warrick RM (1999) Monoamine control of the pacemaker kernel and cycle frequency in the lobster pyloric rhythm. J Neurosci 19:6712-6722.

Bartos M, Nusbaum MP (1997) Intercircuit control of motor pattern modulation by presynaptic inhibition. J Neurosci 17:2247-2256.

Bartos M, Manor Y, Nadim F, Marder E, Nusbaum MP (1999) Coordination of fast and slow rhythmic neuronal circuits. J Neurosci 19:6650-6660.

Beenhakker MP, Hertzberg S, Nusbaum MP (2000) Neural network modulation by mechanosensory activation. Soc Neurosci Abstr 26:449.

Blitz DM, Nusbaum MP (1997) Motor pattern selection via inhibition of parallel pathways. J Neurosci 17:4965-4975.

Blitz DM, Nusbaum MP (1999) Distinct functions for cotransmitters mediating motor pattern selection. J Neurosci 19:6774-6783.

Blitz DM, Beenhakker MP, Nusbaum MP (1998) Motor pattern selection via projection neuron selection. Soc Neurosci Abstr 24:1890.

Blitz DM, Christie AE, Coleman MJ, Norris BJ, Marder E, Nusbaum MP (1999) Different proctolin neurons elicit distinct motor patterns from a multifunctional neuronal network. J Neurosci 19:5449-5463.

Brezina V, Weiss KR (1997) Analyzing the functional consequences of transmitter complexity. Trends Neurosci 20:538-543.

Christie AE, Lundquist CT, Nässel DR, Nusbaum MP (1997a) Two novel tachykinin-related peptides from the nervous system of the crab Cancer borealis. J Exp Biol 200:2279-2294.

Christie AE, Wood DE, Nusbaum MP (1997b) A neuromodulatory role for Cancer borealis tachykinin-related peptide Ia in the crab stomatogastric ganglion. Soc Neurosci Abstr 23:476.

Coleman MJ (1995) Dynamic modulation of a rhythmically active neural network in the stomatogastric nervous system of the crab, Cancer borealis. $\mathrm{PhD}$ thesis, University of Alabama at Birmingham.

Coleman MJ, Nusbaum MP (1994) Functional consequences of compartmentalization of synaptic input. J Neurosci 14:6544-6552.

Coleman MJ, Konstant PH, Rothman BS, Nusbaum MP (1994) Neuropeptide degradation produces functional inactivation in the crustacean nervous system. J Neurosci 14:6205-6216.

Coleman MJ, Meyrand P, Nusbaum MP (1995) A switch between two modes of synaptic transmission mediated by presynaptic inhibition. $\mathrm{Na}$ ture 378:502-505.

Flamm RE, Harris-Warrick RM (1986) Aminergic modulation in lobster stomatogastric ganglion. I. Effects on motor pattern and activity of neurons within the pyloric circuit. J Neurophysiol 55:847-865.

Folkers K, Hakanson R, Horig J, Xu JC, Leander S (1984) Biological evaluation of substance P antagonists. Br J Pharmacol 83:449-456.

Harris-Warrick RM, Marder E, Selverston A, Moulins M (1992) Dynamic biological networks: the stomatogastric nervous system. Cambridge, MA: MIT.

Hokfelt T (1991) Neuropeptides in perspective: the last ten years. Neuron 7:867-879.

Hurwitz I, Perrins R, Xin Y, Weiss K, Kupfermann I (1999) C-PR neuron of Aplysia has differential effects on "feeding" cerebral interneurons, including myomodulin-positive CBI-12. J Neurophysiol 81:521-533.

Jan LY, Jan YN (1982) Peptidergic transmission in sympathetic ganglia of the frog. J Physiol (Lond) 327:219-246.

Kulhman JR, Li C, Calabrese RL (1985a) FMRF-amide-like substances in the leech. I. Immunocytochemical localization. J Neurosci 5:2301-2309.

Kulhman JR, Li C, Calabrese RL (1985b) FMRF-amide-like substances in the leech. II. Bioactivity on the heartbeat system. J Neurosci 5:2310-2317.

Marder E, Jorge-Rivera JC, Kilman V, Weimann JM (1997) Peptidergic modulation of synaptic transmission in a rhythmic motor system. Adv Organ Biol 2:213-233.

Mayeri E, Rothman BS, Brownell PH, Branton WD, Padgett L (1985) Nonsynaptic characteristics of neurotransmission mediated by egg-laying hormone in the abdominal ganglion of Aplysia. J Neurosci 5:2060-2077.

McCrohan CR, Croll RP (1997) Characterization of an identified cerebrobuccal neuron containing the neuropeptide APGWamide (Ala-Pro-GlyTrp- $\mathrm{NH}_{2}$ ) in the snail Lymnaea stagnalis. Invert Neurosci 2:273-283.

Nadim F, Manor Y, Nusbaum MP, Marder E (1998) Frequency regulation of a slow rhythm by a fast periodic input. J Neurosci 18:5033-5067.
Nässel DR (1999) Tachykinin-related peptides in invertebrates: a review. Peptides 20:141-158.

Norris BJ, Coleman MJ, Nusbaum MP (1994) Recruitment of a projection neuron determines gastric mill motor pattern selection in the stomatogastric nervous system of the crab, Cancer borealis. J Neurophysiol 72:1451-1463.

Norris BJ, DM Blitz, Nusbaum MP (1995) Dye-coupling between projection axon terminals and network neurons in the crab stomatogastric nervous system. Soc Neurosci Abstr 21:150.

Norris BJ, Coleman MJ, Nusbaum MP (1996) Pyloric motor pattern modification by a newly identified projection neuron in the crab stomatogastric nervous system. J Neurophysiol 75:97-108.

Nusbaum MP, Marder E (1989a) A modulatory proctolin-containing neuron (MPN). I. Identification and characterization. J Neurosci 9:1591-1599.

Nusbaum MP, Marder E (1989b) A modulatory proctolin-containing neuron (MPN). II. State-dependent modulation of rhythmic motor activity. J Neurosci 9:1600-1607.

Nusbaum MP, Wood DE (1999) The role of cotransmitters and peptidase activity in shaping the actions of peptidergic neurons. Soc Neurosci Abstr 25:1967.

Roques BP, Noble F, Daugé V, Fournié-Zaluski MC, Beaumont A (1993) Neutral endopeptidase 24.11: structure, inhibition, and experimental and clinical pharmacology. Pharmacol Rev 45:87-146.

Rose C, Vargas F, Facchinetti P, Bourgeat P, Bambal RB, Bishop PB, Chan SMT, Moore ANJ, Ganellin CR, Schwartz J-C (1996) Characterization and inhibition of a cholecystokinin-inactivating serine peptidase. Nature 380:403-411.

Saleh TM, Kombian SB, Zidichouski JA, Pittman QJ (1996) Peptidergic modulation of synaptic transmission in the parabrachial nucleus in vitro: importance of degradative enzymes in regulating synaptic efficacy. J Neurosci 16:6046-6055.

Sigvardt KA, Rothman BS, Brown RO, Mayeri E (1986) The bag cells of Aplysia as a multitransmitter system: identification of alpha bag cell peptide as a second neurotransmitter. J Neurosci 6:803-813.

Squire CR, Talebian M, Menon JG, Dekruyff S, Lee TD, Shively JE, Rothman BS (1991) Leucine aminopeptidase-like activity in Aplysia hemolymph rapidly degrades biologically active alpha-bag cell peptide fragments. J Biol Chem 266:22355-22363.

Swensen A, Golowasch J, Christie AE, Coleman MJ, Nusbaum MP, Marder E (2000) GABA and GABA responses in the stomatogastric ganglion of the crab Cancer borealis. J Exp Biol 203:2075-2092.

Thorogood MSE, Brodfuehrer PD (1995) The role of glutamate in swim initiation in the medicinal leech. Invert Neurosci 1:223-233.

Turner AJ, Hooper NM, Kenny AJ (1987) Metabolism of neuropeptides. In: Mammalian ectoenzymes (Kenny AJ, Turner AJ, eds), pp 211-248. London: Elsevier Science.

Vilim FS, Cropper EC, Price DA, Kupfermann I, Weiss KR (2000) Peptide cotransmitter release from motorneuron B16 in Aplysia californica: costorage, corelease, and functional implications. J Neurosci 20:2036-2042

Weimann JM, Marder E (1994) Switching neurons are integral members of multiple oscillatory networks. Curr Biol 4:896-902.

Weimann JM, Meyrand P, Marder E (1991) Neurons that form multiple pattern generators: Identification and multiple activity patterns of gastric/pyloric neurons in the crab stomatogastric system. J Neurophysiol 65:111-122.

Weimann JM, Skiebe P, Heinzel H-G, Soto C, Kopell N, Jorge-Rivera JC, Marder E (1997) Modulation of oscillator interactions in the crab stomatogastric ganglion by crustacean cardioactive peptide. J Neurosci $17: 1748-1760$.

Wood DE, Nusbaum MP (1998) Different modulatory neurons elicit distinct circuit responses despite common cotransmitters. Soc Neurosci Abstr 23:1890.

Xin Y, Hurwitz I, Perrins R, Evans CG, Alexeeva V, Weiss KR, Kupfermann I (1999) Actions of a pair of identified cerebral-buccal interneurons (CBI-8/9) in Aplysia that contain the peptide myomodulin. J Neurophysiol 81:507-520.

Zappulla JP, Wickham L, Bawab W, Yang X-F, Storozhuk MV, Castellucci VF, DesGroseillers L (1999) Cloning and characterization of Aplysia neutral endopeptidase, a metallo-endopeptidase involved in the extracellular metabolism of neuropeptides in Aplysia californica. J Neurosci 19:4280-4292.

Zupanc GKH (1996) Peptidergic transmission: from morphological correlates to functional implications. Micron 27:35-91. 